\title{
Editorial
}

\section{Gene Therapy and Infection Control: More Light on the Way}

\author{
Larry J. Strausbaugh, MD
}

Last year this Journal ushered many readers into the brave new world of gene therapy. Prior to that time, many hospital epidemiologists and infection control practitioners had not considered the implications of this evolving therapeutic modality. If they had thought about it at all, they may have regarded gene therapy as only a small cloud on the distant horizon that likely would not trouble their future careers, a topic more suited for science fiction than serious discussion. That mindset changed forever with an article entitled "Infection Control in Gene Therapy" by Evans and Lesnaw $^{1}$ and the accompanying editorial by Weber and Rutala, ${ }^{2}$ both of which appeared in the August 1999 issue of this Journal. These authors made us aware of the numerous gene therapy studies already underway in various parts of the world. At the same time, they introduced us to the terminology, the vectors, the disease targets, and the infection control concerns. Finally, they outlined a framework for managing patients and healthcare workers caught up in this dynamic enterprise. Hospital epidemiologists and infection control practitioners could no longer fail to see the relevance and immediacy of this new technology or to say that they had not been alerted.

The current issue of the Journal delivers a reminder and update on this topic in the Special Report from a multidisciplinary conference on clinical infection control in gene therapy that took place last fall. ${ }^{3}$ This report provides a review of the vectors, their potential applications, and national regulatory activity provided by the National Institutes of Health (NIH) Recombinant DNA Advisory Committee (RAC), and the Food and Drug Administration (FDA). In addition, it offers perspective from the Director of the Hospital Infections Program at the Centers for Disease Control and Prevention and detailed infection control considerations for the various types of vectors. This report builds on the foundation provided in the 1999 articles and gives readers additional incentives to find out what is happening in their own institutions, referral centers, and communities.

Numerous observations attest to the ongoing ferment and activity in the field of gene therapy, which will likely expand and draw more healthcare facilities and their infection control programs into the process. The number of active protocols and enrolled subjects has continued to grow. As of May 25, 2000, 425 gene therapy protocols had enrolled 3,476 patients worldwide. ${ }^{4}$ Although $70 \%$ of the protocols and $65 \%$ of the enrolled patients derive from the United States, it is truly a global activity, involving countries in Europe, Asia, and Africa, as well as Australia. Most of this research activity has been launched in the last 5 years.

Even a cursory review of the medical literature indicates how research in the field of gene therapy has continued to grow. A recent MEDLINE search on the term gene therapy yielded 4,534 citations since 1997. The number of new citations per year has increased almost 10 -fold in the last decade, from 177 in 1990 to 1,527 in 1999. The medical literature also attests to expansions in the scope of gene therapy applications. The field has moved far beyond hereditary diseases amenable to cure by replacement of one gene product. Recent review articles discuss the prospect of gene therapy for diabetes mellitus, ${ }^{5}$ rheumatic diseases, ${ }^{6}$ gliomas, ${ }^{7}$ Parkinson's disease, ${ }^{8}$ prostate and bladder cancer, ${ }^{9,10}$ osteoinduction, ${ }^{11}$ lung cancer, ${ }^{12}$ hepatic diseases, ${ }^{13}$ cardiovascular diseases, ${ }^{14}$ and a host of other conditions. Moreover, one finds these types of articles scattered among the journals of virtually all medical specialties and subspecialties-for example, plastic surgery, ${ }^{15}$ or thopedics, ${ }^{11}$ and urology, 9,10 to name a few. This observation suggests that hospital epidemiologists and infection control 
practitioners may find gene therapy technology entering their facilities in the disciplines where they least expect it.

The medical literature on gene therapy pales in comparison to information available on the Internet. For example, a search on the term genettherapy using the Lycos search engine retrieves more than 90,000 web sites and 4,500 news articles dealing with this topic. In a quick perusal of the first hundred entries or so, one finds the sites of peer-reviewed journals; academic, research, or healthcare institutions; commercial sources of reagents; various professional societies; conference announcements or proceedings; disease-oriented web pages, eg, one on acquired immunodeficiency syndrome; web pages focused on other conditions (eg, baldness was mentioned on at least six); ethics-oriented web pages; etc. Of course, a few sites were dedicated to helping one navigate through all of the other sites concerned with gene therapy. Other search engines appeared to offer similar results. These observations emphasize the unparalleled access that our patients and their families may have to resources for gene therapy. Such patients may bring the products of these resources into our communities or healthcare facilities without prior notification of, or preparation by, infection control staff.

With the announcement this year that the "working draft" of the human genome is complete, expectations for gene therapy have continued to soar. Utilization of the technology will accelerate and further challenge infection control programs if trials in progress yield positive results.

To date, gene therapy lacks an unequivocal clinical success. ${ }^{16}$ However, there is reason for hope. Two research groups reported favorable preliminary results at the annual meeting of the American Society of Hematology in January. ${ }^{17} \mathrm{~A}$ team of French investigators described encouraging results in two children with $\mathrm{X}$-linked severe combined immunodeficiency disease, whose CD34 stem cells were infected ex vivo with a retroviral vector containing the gene encoding the $\gamma$-common chain. An American team reported encouraging results in three patients with hemophilia B who received intramuscular injections of a replication-deficient adeno-associated virus containing the gene that encodes factor IX. If these preliminary results hold up or if other positive studies appear, the momentum for gene therapy approaches surely will intensify.

The news about gene therapy is not always good, and this too has an impact on infection control concerns. The death of an 18-year-old man with ornithine transcarbamylase (OTC) deficiency who was enrolled in a study at the University of Pennsylvania has received widespread publicity during the last year, heightening concerns about the dark side of this technology. The patient, who had received intrahepatic arterial injections of an adenovirus vector containing the OTC transgene, died of "a diffuse activation of his immune system" and multiple organ failure within 4 days of receiving the vector. ${ }^{18}$ The study was halted immediately, and concerns about protocol violations were aired in the media. The FDA subsequently halted eight other studies at the same institution, as well as one multicenter study elsewhere. ${ }^{19}$
Naturally, this negative publicity fuels anxiety in those who question the wisdom of "fooling mother nature." It also fosters formation of a constituency that will oppose all gene therapy trials and challenge the adequacy of any framework for ensuring the safety of patients, healthcare workers, and visitors. Consequently, in yet another circumstance infection control programs will confront a serious issue, dealing with a mixture of reasonable, anxious, and overcritical individuals.

So, this is the larger context in which I read the report from the multidisciplinary conference on infection control in gene therapy that is published in this month's issue. As a hospital epidemiologist who has not yet dealt directly with the ramifications of an in-house gene therapy protocol, I experienced a number of contradictory thoughts and emotions as I read the report. At the outset, I resolved again to maintain regular contact with the Chairman of our Institutional Review Board to be sure that I am "in the loop" for review of gene therapy protocols (and wondered what has happened since I last did this). I further resolved to check with my counterpart at our adjoining medical center to find out where they stand. (Perhaps, without knowing it, I have already had some personal exposure to patients treated with gene therapy while attending on one of their units.) I wished that I could find out more about gene therapy research in my community. There may be lots of animal research in progress. There may also be clinical trials underway in other medical centers, commercially oriented networks of contract-research organizations, or sitemanagement organizations. The latter two organizations, which are independent of academic medical centers, play an increasingly prominent role in clinical research for pharmaceutical companies. ${ }^{20}$

As I read about the oversight offered by the NIH, Recombinant DNA Advisory Committee, and FDA, I breathed a sigh of relief. Clearly, as the report indicates, these agencies have taken the potential problems very seriously and have collected a wealth of reassuring data on safety issues. Nevertheless, aroused by the death of the patient at the University of Pennsylvania last fall, the agencies recently launched two new initiatives to improve protection for patients in gene therapy studies ${ }^{21}$ : One seeks to intensify the level of oversight by requiring researchers to submit their monitoring plans routinely to the FDA; the other calls for public meetings that will bring gene therapy researchers together regularly to discuss important topics about safety. In remembering these initiatives, I found myself wondering about the adequacy of the review and monitoring process. How do I know that we will not need new initiatives down the road to cover some gap in the current plan, unmasked by an unexpected complication?

As I read about the various viral vectors, I initially found comfort in noting that, to date, no reports have described secondary infections in association with gene therapy. But then, as I read about the use of replicationcompetent strains of vaccinia in some studies, I became uneasy again. The possibility of recombinations in vivo raised the greatest fear. 
I kept reading and finally came to the sections on infection control. These provided the perspective and practical approach to deal with the concerns and uncertainties that necessarily accompany gene therapy. They start with what is known and use both scientific principles and sound logic to address the various situations that are likely to be encountered. Six phases in the process of gene therapy form the loci for scrutiny and, possibly, action by infection control staff: vector characterization, patient preparation, vector introduction, initial distribution and shedding, replication, and recombination. Subsequently in the reports, these phases are used to review the management of patients receiving various types of viral vectors. One additional section reviews the experience of the infection control program in gene therapy research at the University of North Carolina. The infection control protocol used in their cystic fibrosis study has been published previously. ${ }^{22}$

Overall, the Special Report in this issue of the Journal advances considerably our understanding of the infection control issues that pertain to gene therapy. It also offers a practical approach to managing these issues, which builds upon existing knowledge, applies sound epidemiological principles, and utilizes current conventions for preventing nosocomial infections. At present, this report provides the clearest and most comprehensive guidelines for managing the infection control aspects of gene therapy. In the absence of authoritative guidelines from other sources, it serves as a beacon to direct us from the known into the unknown of this rapidly expanding and somewhat scary field.

\section{REFERENCES}

1. Evans ME, Lesnaw JA. Infection control in gene therapy. Infect Control Hosp Epidemiol 1999;20:568-576.
2. Weber DJ, Rutala WA. Gene therapy: a new challenge for infection control. Infect Control Hosp Epidemiol 1999;20:530-532.

3. Evans ME, Jordan CT, Chang SMW, Conrad C, Gerberding JL, Kaufman $\mathrm{HL}$, et al. Clinical infection control in gene therapy: a multidisciplinary conference. Infect Control Hosp Epidemiol 2000;21:659-673.

4. The Journal of Gene Medicine Website. The Clinical Trials Website. Charts and Statistics. http://www.wiley.co.uk/genmed/clinical/charts/ 1 countries.html. Last updated May 25, 2000.

5. Giannoukakis N, Rudert WA, Robbins PD, Trucco M. Targeting autoimmune diabetes with gene therapy. Diabetes 1999;48:2107-2121.

6. Evans CH, Ghivizzani SC, Kang R, Muzzonigro T, Wasko MC, Herndon $\mathrm{JH}$, et al. Gene therapy for rheumatic diseases. Arthritis Rheum 1999;42:1-16.

7. Fueyo J, Gomez-Manzano C, Yung WK, Kyritsis AP. Targeting in gene therapy for gliomas. Arch Neurol 1999;56:445-448.

8. Freese A. Restorative gene therapy approaches to Parkinson's disease. Med Clin North Am 1999;83:537-548.

9. Palapattu GS, Naitoh J, Belldegrun AS. Gene therapy for prostate cancer. New perspectives on an old problem. Urol Clin North Am 1999;26:353-363.

10. Hsieh JT, Dinney CP, Chung LW. The potential role of gene therapy in the treatment of bladder cancer. Urol Clin North Am 2000;27:103-113.

11. Scaduto AA, Lieberman JR Gene therapy for osteoinduction. Orthop Clin North Am 1999;30:625-633.

12. Albelda SM, Wiewrodt R, Zuckerman JB. Gene therapy for lung disease: hype or hope? Ann Intern Med 2000;132:649-660.

13. Shetty K, Wu GY, Wu CH. Gene therapy of hepatic diseases: prospects for the new millennium. Gut 2000;46:136-139.

14. Duckers HJ, Nabel EG. Prospects for genetic therapy of cardiovascular disease. Med Clin North Am 2000;84:199-213.

15. Taub PJ, Silver L, Weinberg H. Plastic surgical perspectives on vascular endothelial growth factor as gene therapy for angiogenesis. Plast Reconstr Surg 2000;105:1034-1042.

16. Smith AE. Gene therapy—where are we? Lancet 1999;354(suppl 1):SI1-SI4.

17. Stephenson J. Gene therapy trials show clinical efficacy. JAMA 2000;283:589-590.

18. Barbour V. The balance of risk and benefit in gene-therapy trials. Lancet $2000 ; 355: 384$

19. McCarthy M. FDA puts US gene-therapy trial on hold. Lancet 2000;355:908-910.

20. Bodenheimer T. Uneasy alliance: clinical investigators and the pharmaceutical industry. $N$ Engl J Med 2000;342:1539-1544.

21. Stephenson J. Gene therapy trial oversight. JAMA 2000;283:1950.

22. Israel BF, Weber DJ, Rutala WA. Infection control in gene therapy. In: Mayhall CG, ed. Hospital Epidemiology and Infection Control. 2nd ed. Philadelphia, PA: Lippincott Williams \& Wilkins; 1999:1015-1020. 